CLINICAL STUDY

\title{
Testosterone therapy decreases subcutaneous fat and adiponectin in aging men
}

\author{
L Frederiksen $^{1,2}$, K Højlund ${ }^{1,2}$, D M Hougaard ${ }^{3}$, T H Mosbech ${ }^{4}$, R Larsen ${ }^{4}$, A Flyvbjerg ${ }^{5,6}$, J Frystyk ${ }^{5,6}$, K Brixen ${ }^{1,2}$ \\ and M Andersen ${ }^{1,2}$ \\ ${ }^{1}$ Department of Endocrinology, Odense University Hospital, Sdr. Boulevard 29, 5000 Odense C, Denmark, ${ }^{2}$ Institute of Clinical Research, University of \\ Southern Denmark, Odense, Denmark, ${ }^{3}$ Department of Clinical Biochemistry and Immunology, Statens Serum Institut, Artillerivej, 2300 Copenhagen S, \\ Denmark, ${ }^{4}$ DTU Informatics, Technical University of Denmark, Kgs. Lyngby, Denmark, ${ }^{5}$ The Medical Research Laboratories, Faculty of Health Sciences, \\ Clinical Institute of Medicine, Aarhus University, Aarhus C, Denmark and ${ }^{6}$ Department of Endocrinology and Internal Medicine, Aarhus University \\ Hospital, 8000 Aarhus C, Denmark
}

(Correspondence should be addressed to L Frederiksen at Department of Endocrinology, Odense University Hospital; Email: louise.frederiksen@ouh.regionsyddanmark.dk)

\begin{abstract}
Objective: Testosterone therapy increases lean body mass and decreases total fat mass in aging men with low normal testosterone levels. The major challenge is, however, to determine whether the metabolic consequences of testosterone therapy are overall positive. We have previously reported that 6-month testosterone therapy did not improve insulin sensitivity. We investigated the effect of testosterone therapy on regional body fat distribution and on the levels of the insulin-sensitizing adipokine, adiponectin, in aging men with low normal bioavailable testosterone levels.

Design: A randomized, double-blinded, placebo-controlled study on 6-month testosterone treatment (gel) in 38 men, aged 60-78 years, with bioavailable testosterone $<7.3 \mathrm{nmol} / \mathrm{l}$, and a waist circumference $>94 \mathrm{~cm}$.

Methods: Central fat mass (CFM) and lower extremity fat mass (LEFM) were measured by dual X-ray absorptiometry. Subcutaneous abdominal adipose tissue (SAT), visceral adipose tissue (VAT), and thigh subcutaneous fat area (TFA) were measured by magnetic resonance imaging. Adiponectin levels were measured using an in-house immunofluorometric assay. Coefficients $(b)$ represent the placebocontrolled mean effect of intervention.

Results: LEFM was decreased $(b=-0.47 \mathrm{~kg}, P=0.07)$ while CFM did not change significantly $(b=-0.66 \mathrm{~kg}, P=0.10)$ during testosterone therapy. SAT $(b=-3.0 \%, P=0.018)$ and TFA $(b=-3.0 \%, P<0.001)$ decreased, while VAT $(b=1.0 \%, P=0.54)$ remained unchanged. Adiponectin levels decreased during testosterone therapy $(b=-1.3 \mathrm{mg} / \mathrm{l}, P=0.001)$.

Conclusion: Testosterone therapy decreased subcutaneous fat on the abdomen and lower extremities, but visceral fat was unchanged. Moreover, adiponectin levels were significantly decreased during testosterone therapy.
\end{abstract}

European Journal of Endocrinology 166 469-476

\section{Introduction}

Testosterone therapy has been almost universally found to increase lean body mass (LBM) and decrease total fat mass (TFM) (1) in accordance with our data in aging men with low normal bioavailable testosterone levels (2). Theoretically, these beneficial changes would improve insulin sensitivity. However, we found no increase in insulin sensitivity using the hyperinsulinemic euglycemic clamp (2). The probable explanations for the lack of improvement in insulin sensitivity are complex and interrelated. Thus, the decrease in TFM during testosterone therapy may predominantly involve fat on the lower extremities, which has been reported to be positively associated with insulin sensitivity (3). Alternatively, testosterone therapy may reduce the insulin-sensitizing adipokine, adiponectin, and hence have counteracted the overall positive changes in body composition. Adiponectin levels could be decreased either indirectly through a decrease in fat on lower extremities, as fat on the lower extremities has been positively associated with adiponectin levels (4), or due to a direct effect of testosterone on adiponectin secretion (5). Regarding the effect of testosterone therapy on regional fat distribution, studies on abdominally obese, aging men have been conflicting, probably due to the use of oral preparations of testosterone $(6,7,8)$. Studies that used sufficient testosterone doses reported a significant decrease in subcutaneous fat on the abdomen (SAT), but no change in visceral adipose tissue (VAT) during testosterone therapy $(9,10)$, whereas an old study on middle-aged obese men with 
higher baseline testosterone levels reported no change in SAT and a decrease in VAT (11). Data on changes in lower extremity fat during testosterone therapy are limited. Regarding adiponectin, a direct suppressive effect of testosterone therapy on adiponectin levels has been suggested. Clinical studies on the effect of testosterone therapy have reported a decrease in adiponectin levels in men with type 2 diabetes mellitus (12) and in aging men using supraphysiological doses of testosterone (13), while no changes were observed in adiponectin levels in aging men treated with physiological doses of testosterone (14). However, changes in regional fat distribution or insulin sensitivity were not measured in these studies. Therefore, in this study, we assessed the effect of 6-month testosterone therapy on the regional fat distribution measured by dual X-ray absorptiometry (DXA) and magnetic resonance imaging (MRI) and adiponectin levels in abdominally obese, aging men with low normal bioavailable testosterone levels (15).

\section{Methods}

The study was a single-center, randomized, placebocontrolled, double-blinded study to assess the effect of testosterone gel and strength training on body composition, components of the metabolic syndrome, and quality of life in men aged 60-78 years with low normal bioavailable testosterone levels and increased body fat. In this study, we report only the results from the testosterone and placebo groups. The study was approved by the local ethics committee and declared in ClinicalTrials.gov (identifier: NCT00700024). All participants gave written informed consent. Recruitment of participants and study population have been described elsewhere (2).

\section{Study design}

Subjects were randomly assigned to receive testosterone $(n=23)$ or placebo $(n=23)$. Randomization numbers were assigned to the participants in order of enrollment into the study. The randomization list, medicine labeling, randomization, and code break envelopes were generated by Ipsen Scandinavia (Kista, Stockholm, Sweden) to ensure double blinding.

In the testosterone group, participants initially received $5 \mathrm{~g}$ gel $(50 \mathrm{mg}$ testosterone, Testim; Ipsen, France), or $5 \mathrm{~g}$ gel (placebo). After 3 weeks of treatment, safety parameters, and testosterone levels were evaluated. If bioavailable testosterone levels were $<7.3 \mathrm{nmol} / \mathrm{l}$, the dose was increased by $10 \mathrm{~g}$ gel (100 mg testosterone). In the placebo group, the dose was increased in all participants, and in the testosterone group, the dose was increased in 8/20 participants. Compliance was monitored by participants selfreporting at each visit. Three subjects in the testosterone group and five subjects in the placebo group prematurely discontinued treatment as described elsewhere (2).

In total, 18 participants in the placebo group and 20 in the testosterone group completed the study. Two participants in the placebo group and one participant in the testosterone group did not complete the MRI scans due to claustrophobia. Measurements of prostatespecific antigen, hemoglobin, and hematocrit were conducted at baseline, after 3 weeks, 3 months, and 6 months of therapy. Safety monitoring was externally handled to ensure continued blinding. Digital rectal examination of the prostate was performed to record changes at baseline and after 3 and 6 months. Subjects were advised to refrain from all self-initiated resistance exercise training and intense endurance training but were allowed to continue other habitual activities throughout the study. Subjects were informed not to change their diet. The study outcomes were evaluated at baseline and 6 months.

There was no significant difference between participants in the placebo group and the testosterone group at baseline regarding age, body mass index (BMI), waist circumference (WC), LBM, and TFM (Table 1) (2). There was no significant difference between participants in the placebo group and the testosterone group at baseline regarding total testosterone (TT), free testosterone (FT) and bioavailable testosterone (BT), LH, fasting insulin, or insulin sensitivity measured by the euglycemic hyperinsulinemic clamp (Rd; Table 2) (2).

\section{Dual X-ray absorptiometry}

TFM, central fat mass (CFM), lower extremity fat mass (LEFM), and LBM were measured by DXA using a Hologic Discovery Device (Waltham, MA, USA). The coefficient of variation $(\mathrm{CV})$ was $0.8 \%$ for TFM and $0.6 \%$ for LBM.

\section{Magnetic resonance imaging}

MRI was performed using a 3.0 Tesla High field MR Unit (Philips Achieva, Phillips Healthcare, Best, The Netherlands). One abdominal slice (10 mm-thick, intervertebral space of L4/L5, perpendicular to subcutaneous fat) was recorded using an axial, T1-weighted gradient-echo sequence (repetition time (TR) $150 \mathrm{~ms}$, echo time (TE) $2.3 \mathrm{~ms}$, acquisition matrix $328 \times 254$, field of view $450 \times 450 \mathrm{~mm}$ ). Computer software (16)

Table 1 Baseline data (2). Values are given as median (interquartile range).

\begin{tabular}{lcc}
\hline & Testosterone & Placebo \\
\hline Age (years) & $68(62-72)$ & $67(65-69)$ \\
WC $(\mathrm{cm})$ & $107(104-114)$ & $105(98-118)$ \\
BMI $\left(\mathrm{kg} / \mathrm{m}^{2}\right)$ & $29.8(27.7-32.9)$ & $29.2(26.4-33.6)$ \\
Total fat mass $(\mathrm{kg})$ & $24.4(21.6-30.7)$ & $23.9(18.9-32.8)$ \\
Lean body mass $(\mathrm{kg})$ & $64.6(57.4-71.2)$ & $64.7(58.8-72.7)$ \\
\hline
\end{tabular}


Table 2 Total testosterone, bioavailable testosterone, free testosterone, SHBG, LH, fasting insulin, and insulin sensitivity at baseline and after 6 months of testosterone therapy (2). Values are given as median (interquartile range).

\begin{tabular}{|c|c|c|c|c|}
\hline & \multicolumn{2}{|c|}{ Testosterone } & \multicolumn{2}{|c|}{ Placebo } \\
\hline & Start & 6 months & Start & 6 months \\
\hline Total testosterone (nmol/l) & $12.2(9.5-15.7)$ & $18.7(14.9-25.4)^{\dagger}$ & $12.6(8.8-17.1)$ & $10.6(8.2-11.0)$ \\
\hline Bioavailable testosterone (nmol/l) & $5.1(4.3-6.0)$ & $9.7(6.6-13.4)^{\dagger}$ & $4.4(3.3-5.9)$ & $3.9(3.5-4.6)$ \\
\hline Free testosterone $(\mathrm{nmol} / \mathrm{l})$ & $0.27(0.22-0.32)$ & $0.43(0.29-0.62)^{\dagger}$ & $0.23(0.18-0.31)$ & $0.21(0.18-0.24)$ \\
\hline SHBG $(\mathrm{nmol} / \mathrm{l})$ & $36(25-62)$ & $33(25-50)$ & $44(39-56)$ & $39(35-51)$ \\
\hline $\mathrm{LH}(\mathrm{IE} / \mathrm{I})$ & $4.6(3.1-7.6)$ & $0.1(0.1-0.75)^{\dagger}$ & $4.1(2.9-6.6)$ & $4.4(2.7-6.5)$ \\
\hline Fasting insulin (pmol/l) & $52(36-96)$ & $48(39-109)$ & $56(36-65)$ & $49(33-75)$ \\
\hline Insulin-stimulated Rd (mg/min per $\left.\mathrm{m}^{2}\right)$ & $207.0(149.5-279.0)$ & $238.65(175.4-288.6)$ & $189.1(148.0-350.1)$ & $234.9(174.2-284.6)$ \\
\hline
\end{tabular}

Insulin-stimulated Rd, insulin-stimulated whole body glucose utilization. ${ }^{\dagger} P<0.01$ compared with placebo.

was used to trace the different compartments of fat on the abdomen and for assessment of the areas of SAT and VAT. The thigh fat area (TFA) was determined on one femoral slice $(15 \mathrm{~cm}$ from the major trochanter and perpendicular to subcutaneous fat) using a T1-weighted gradient-echo sequence (TR $400 \mathrm{~ms}$, TE $18 \mathrm{~ms}$, acquisition matrix $376 \times 335$, field of view $230 \times 230 \mathrm{~mm}$ ). Computer software (16) was used to trace fat and muscle compartments on the thigh to assess TFA and thigh muscle area (TMA).

\section{Hormones and SHBG}

Testosterone was measured between 0800 and $0900 \mathrm{~h}$ after an overnight fast. Serum TT was measured by liquid chromatography tandem mass spectrometry after ether extraction.

For testosterone measurements, the intra-assay $\mathrm{CV}$ was $<10 \%$ for TT $>0.2 \mathrm{nmol} / \mathrm{l}$ and $\mathrm{CV}$ was $<30 \%$ in the range between 0.1 and $0.2 \mathrm{nmol} / \mathrm{l}$.

SHBG was measured by auto-DELFIA, and BT and FT were calculated according to the formulas of Vermeulen et al. (17). A single measurement of testosterone was performed to determine eligibility. BT levels were below $7.3 \mathrm{nmol} / \mathrm{l}(15)$ at re-evaluation after 3 weeks on placebo $(n=18)$.

Adiponectin was determined by an in-house timeresolved immunofluorometric assay as described elsewhere (18), with intra- and interassay CV averaging $<5$ and $10 \%$ respectively. Serum levels of LH were analyzed by time-resolved fluoroimmunoassay using commercial kits (auto-DELFIA; PerkinElmer Life Sciences, Oy, Turku, Finland). Intra-assay $\mathrm{CV}$ was $1.0-9.3 \%$ and interassay CV was $2.3-3.9 \%$.

Serum levels of insulin were analyzed by timeresolved immunofluorometric assay (auto-DELFIA; PerkinElmer Life Sciences). The intra-assay CV was $2.1-3.7 \%$ and the interassay CV was $3.4-4.0 \%$.

\section{Euglycemic hyperinsulinemic clamp}

The clamp protocol has been described in detail elsewhere (2). After a 120 min basal tracer equilibration period, insulin (Actrapid; Novo Nordisk, Bagsvaerd,
Denmark) was infused at a rate of $40 \mathrm{mU} / \mathrm{m}^{2}$ per $\mathrm{min}$ for $180 \mathrm{~min}$. A primed constant $\left[3-{ }^{3} \mathrm{H}\right]$-glucose infusion was used throughout the $300 \mathrm{~min}$ study, and $\left[3-{ }^{3} \mathrm{H}\right]-$ glucose was added to the glucose infusates to maintain plasma-specific activity constant at baseline levels during the $180 \mathrm{~min}$ clamp period as described (19). Plasma glucose levels were clamped at $\sim 5 \mathrm{mmol} / \mathrm{l}$ using a variable infusion rate of $20 \%$ glucose based on bedside plasma glucose measurements (ABL800 Flex; Radiometer, Copenhagen, Denmark) every 10-20 min. The basal and insulin-stimulated steady-state periods were defined as the last $20 \mathrm{~min}$ of the 120 basal and $180 \mathrm{~min}$ insulin infusion period. Tritiated glucosespecific activity was determined on samples deproteinized with barium and zinc as described elsewhere (19). Steele's nonsteady-state formulas were used to calculate rates of glucose disposal (Rd), assuming a glucose distribution volume of $200 \mathrm{ml} / \mathrm{kg}$ body weight and a pool fraction of 0.65 (19). Insulin-stimulated whole body glucose utilization was taken as an estimate of whole-body insulin sensitivity.

\section{Statistical analysis}

The sample size of the study was determined by the effect of testosterone on LBM (type 1 error $(\alpha)=0.05$, type 2 error $(\beta)=0.1$, S.D. $=1.3 \mathrm{~kg}$, minimal relevant difference $($ MIREDIF $)=1.3 \mathrm{~kg}$, and power $(1-\beta)=90 \%)$. This calculation resulted in 15 subjects in each group. We decided to enroll 20 participants in each group

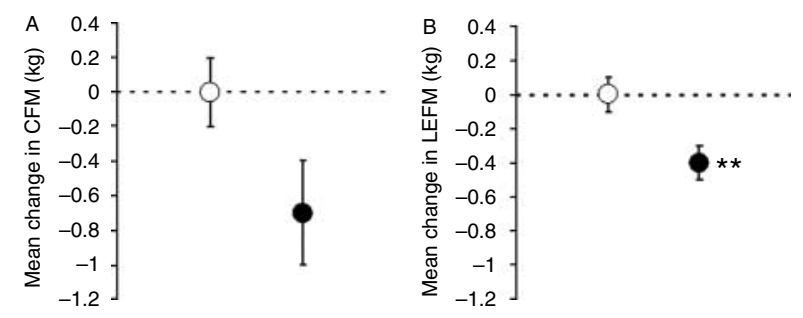

Figure 1 Mean change in central fat mass (CFM) and lower extremity fat mass (LEFM) during testosterone therapy. ${ }^{\star *} P<0.01$; open circle, placebo; closed circle, testosterone. Data are presented as mean \pm S.E.M. 
to allow for dropouts (2). Data were analyzed using Stata version 11. In univariate analysis and in the analysis of correlation of delta values, we used the Pearson correlation. The outcomes were compared by multiple linear regression analysis controlled for baseline values (20). Results are given as the coefficient $(b)$ equivalent to the mean difference in the effect of the intervention (21). The models were checked with residual plots and Box-Cox analysis. Results were considered statistically significant at $P<0.05$. Data are given as median and interquartile range.

\section{Results}

TT, BT, FT, SHBG, LH, fasting insulin, and insulinstimulated $\mathrm{Rd}$ at baseline and after 6-month testosterone therapy are displayed in Table 2 (2).

\section{Body composition}

DXA data At baseline, CFM was 14.0 (12.6-17.5) kg and $13.2(9.2-18.1) \mathrm{kg}$ and LEFM was $6.6(5.7-7.9) \mathrm{kg}$ and $6.9(5.7-9.5) \mathrm{kg}$ in the testosterone and placebo groups respectively. There was no significant difference between participants in the testosterone group and placebo group at baseline regarding CFM and LEFM. LEFM significantly decreased $(b=-0.47 \mathrm{~kg}, P=0.007)$ in response to testosterone therapy whereas CFM was numerically but not statistically reduced CFM $(b=-0.66 \mathrm{~kg}, P=0.10)$ (Fig. $1 \mathrm{~A}$ and $\mathrm{B})$.

MRI data At baseline, there was no significant difference between the testosterone and the placebo groups regarding VAT, SAT, TFA, and TMA. SAT significantly decreased during testosterone therapy $(b=-3.0 \%$ fat area/total area, $P=0.018)$ while VAT was unchanged $(b=1.0 \%$ fat area/total area, $P=0.54)$. TFA decreased $(b=-3.0 \%$ fat area/total area, $P<0.001)$ and TMA increased $(b=3.2 \%$ muscle area/ total area, $P<0.001)$ in response to treatment with testosterone (Fig. 2).

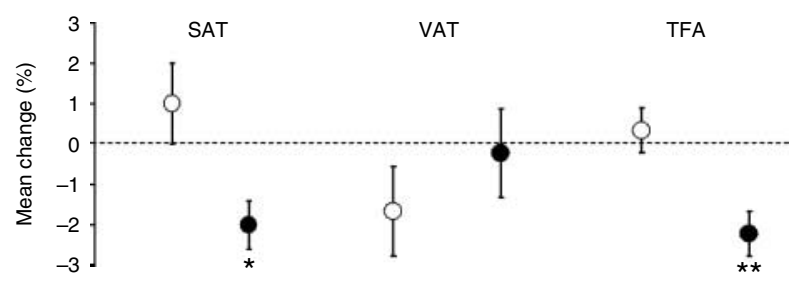

Figure 2 Mean change in subcutaneous adipose tissue on the abdomen (SAT), visceral adipose tissue (VAT), and thigh fat area (TFA). ${ }^{* \star} P<0.01$; ${ }^{\star} P<0.05$; open circle, placebo; closed circle, testosterone. Data are presented as mean \pm S.E.M.

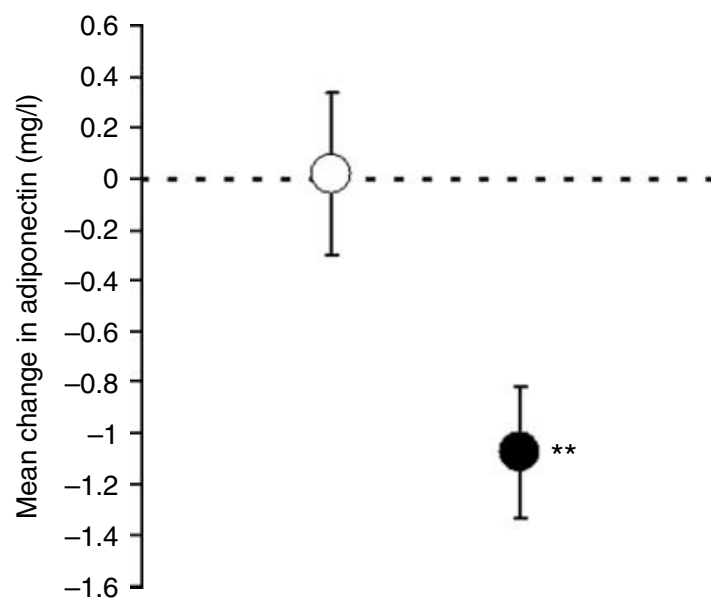

Figure 3 Mean change in adiponectin levels during testosterone therapy. ${ }^{\star \star} P<0.01$; open circle, placebo; closed circle, testosterone. Data are presented as mean \pm S.E.M.

\section{Adiponectin}

There was no significant difference in serum adiponectin levels between the testosterone group (7.2 $(6.3-10.1) \mathrm{mg} / \mathrm{l})$ and the placebo group $(8.6$ $(5.2-10.9) \mathrm{mg} / \mathrm{l})$ at baseline. During testosterone therapy, adiponectin levels decreased in the testosterone group compared with placebo group $(b=-1.3 \mathrm{mg} / \mathrm{l}$, $P=0.001)$, corresponding to $\sim 13 \%$ decrease in adiponectin levels (Fig. 3).

No significant univariate correlations were observed between baseline adiponectin levels in all participants and WC, TFM, CFM, SAT, or VAT or BT. Similarly, no significant correlations were observed between changes in adiponectin levels and changes in WC, TFM, CFM, SAT, VAT, or testosterone levels in participants treated with testosterone.

\section{Discussion}

We conducted a randomized, double-blinded, placebocontrolled study on the effect of testosterone therapy in aging men with a WC $>94 \mathrm{~cm}$ and defined low normal bioavailable testosterone levels (15), assessed using the gold standard testosterone analysis (22). We have previously reported that TFM decreased during testosterone therapy (2). This study extends this finding by showing that the testosterone-induced reduction in fat mass is tissue/area specific. Thus, testosterone therapy significantly decreased subcutaneous fat on the abdomen and on the lower extremities, whereas the amount of VAT remained unchanged. Our data were in agreement with a previous meta-analysis (23) and in agreement with studies on testosterone therapy in aging obese men $(6,8)$. However, no change in TFM was 
observed in nonobese aging men during testosterone therapy (24). Data from randomized placebo-controlled studies on the effect of testosterone treatment on the regional distribution of fat are conflicting (Table 3). In accordance with our results, Svartberg et al. (10) reported a significant decrease in SAT and no change in VAT in abdominally obese, aging men with low normal testosterone measuring regional body composition by computed tomography (CT). Five studies $(6,7$, $8,11,24$ ) have reported results that contradicted our data. Two studies on middle-aged obese men reported a significant decrease in VAT during testosterone therapy $(7,11)$. In one of the studies, the authors used an oral preparation of testosterone and reported no significant change in testosterone levels or LBM (7). In the other study, an increase in testosterone levels was reported; however, no change was found in fat mass or LBM (11), suggesting that the testosterone dose had been insufficient to obtain the expected increase in LBM during testosterone therapy (23). Hence, it could be speculated that the decrease in VAT during testosterone therapy reported by Marin et al. $(7,11)$ may be related to other changes during the experiment. A study on nonobese aging men (24) reported a significant increase in VAT in the placebo group during testosterone therapy. VAT, however, did not decrease in the testosterone-treated group. No change was reported in TFM, SAT, or TFA and the lack of change may be attributable to the fact that the participants in this study were nonobese (24). A decrease in VAT, SAT, and TFA was reported in overweight, aging men during testosterone therapy (8) but the decrease in VAT and SAT was, however, not significant when compared with placebo. The lack of significant effect on SAT and VAT compared with placebo may be due to the relatively short duration of the study, i.e. MRI scans were performed after 12 weeks of treatment, and a relatively low dose of testosterone was used. Finally, a large study found no change in SAT or VAT during testosterone therapy measured by ultrasound; however, ultrasound is relatively insensitive and may fail to detect small changes in SAT and VAT (6).

Genetic studies on the androgen receptor (AR) support our findings. The number of CAG repeats $\left(\mathrm{CAG}_{n}\right)$ within the CAG repeat polymorphism of the androgen receptor has been inversely correlated with the activity of the receptor $(25,26)$. In healthy young men, TFM increased whereas LBM decreased with increasing $\mathrm{CAG}_{n}$, suggesting a direct effect of longer CAG repeats on the testosterone-induced increase in LBM and decrease in TFM (27). Nielsen et al. (27) also reported a significant positive association between increasing CAG repeats and subcutaneous fat on the abdomen and thigh; however, no significant association with VAT was seen. Accordingly, we reported a significant decrease in SAT and TFA, whereas VAT remained unchanged.

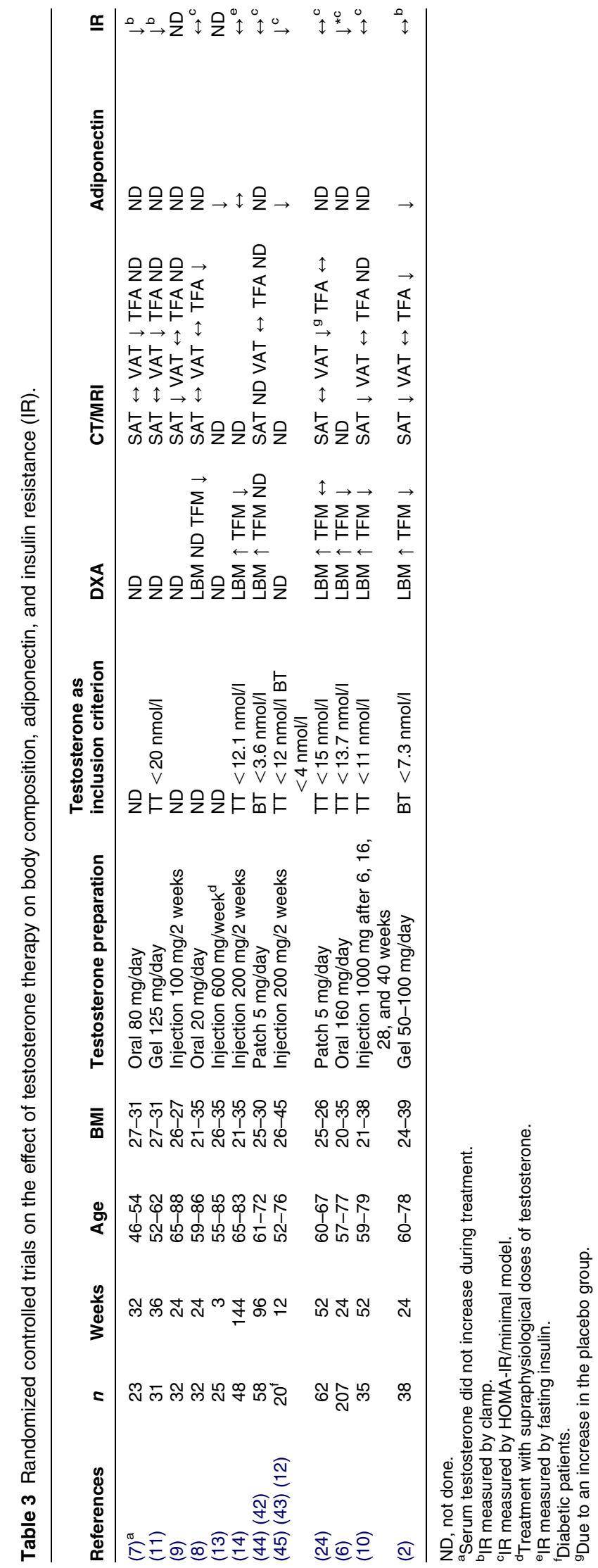

www.eje-online.org 
The adipocyte-derived hormone adiponectin may be a key component in the associations between excess adiposity, insulin resistance, inflammation, and cardiovascular disease (28). A decrease in the circulating levels of adiponectin has been shown to contribute to the development of type 2 diabetes mellitus and the metabolic syndrome (29). In our study, we found a 13\% decrease in adiponectin levels during testosterone therapy. A few randomized double-blinded, placebocontrolled studies have investigated the effect of testosterone therapy on adiponectin levels (Table 1). In accordance with our results, two studies on testosterone therapy in aging men with diabetes (12) and in aging healthy men (13) using supraphysiological doses of testosterone reported a significant decrease in adiponectin of $\sim 20-25 \%$. In contrast, a study of 36 months' duration on sedentary aging men reported no change in adiponectin levels during testosterone therapy (14).

The mechanism of the decrease in adiponectin levels during testosterone therapy is not clear. Theoretically, the negative effect of testosterone therapy on adiponectin levels may be mediated by the change in regional fat. Fat on the lower extremities has been positively associated with adiponectin levels and insulin sensitivity whereas SAT has been negatively associated with adiponectin levels in young (4) and in aging men $(30,31)$. In Prader-Willi syndrome, patients have increased levels of adiponectin compared with weight-matched controls due to increased peripheral distribution of fat and a relatively low amount of central fat. Hence, the decrease in adiponectin may be caused by a decrease in fat on the lower extremities (LEFM and TFA), which is not balanced by the decrease in SAT. Alternatively, testosterone may have a direct suppressive effect on adiponectin levels. Compared with eugonadal men, hypogonadal young men have higher adiponectin levels and adiponectin levels are reduced during testosterone treatment (32). Animal and human fat cell studies have reported increased lipolysis during testosterone exposure $(33,34)$, suggesting that the effect of testosterone therapy on adiponectin levels could be mediated through increased lipolysis (35). Accordingly, $\beta$-adrenergic induction of lipolysis decreased adiponectin secretion in adipocytes (36).

Adiponectin circulates in three different molecular forms: high molecular weight (HMW), medium molecular weight, and low molecular weight. In particular, HMW adiponectin has gained interest as some studies suggest that this molecular form exerts the strongest biological effects (37). However, we did not measure HMW adiponectin as we have previously shown that the strength of the inverse correlation between serum testosterone and the fraction of HMW was similar to that of serum testosterone and total adiponectin ( $r$ values of -0.43 and -0.47 respectively) (38). Consequently, as both measures of adiponectin action showed the same relationship with serum testosterone, we chose to document the effect of testosterone on adiponectin by measurements of total adiponectin.

Interestingly, we reported a decrease in adiponectin levels and an increased basal lipid oxidation during testosterone therapy (2). It has been suggested that adiponectin exerts its insulin-sensitizing effect in part through an increase in lipid oxidation (28). Recombinant globular adiponectin has been shown to increase muscle lipid oxidation in mice via a pathway that involves AMP-activated kinase and acetyl-CoA carboxylase (39). However, as adiponectin levels were decreased during testosterone therapy, our data did not support that the reported increase in lipid oxidation (2) was elicited by adiponectin. Hypothetically, testosterone therapy may have an independent effect on lipid oxidation in muscle; however, further studies are warranted.

In summary, we extended our previous findings by providing further support for the notion that testosterone therapy may have positive as well as negative effects on important metabolic measures. Thus, we reported previously that testosterone therapy had positive effects, e.g. increased LBM, decreased TFM, and increased basal lipid oxidation. However, HDL-cholesterol was decreased during testosterone therapy (2) in agreement with a meta-analysis (40) and a recent systematic review (41); however, in a meta-analysis, Isidori et al. (23) found no change in HDL-cholesterol. Overall insulin sensitivity was unchanged during testosterone therapy in men with low normal testosterone levels (2). However, two recent large studies on testosterone therapy in men with metabolic syndrome and type 2 diabetes mellitus reported a significant decrease in insulin resistance assessed by a surrogate marker of insulin resistance (HOMA-IR) $(42,43)$.

We demonstrated that although testosterone therapy decreased subcutaneous fat on the lower extremities and abdomen, no effect was observed on VAT and the insulin-sensitizing adipokine, adiponectin, was decreased. A decrease in HDL-cholesterol (2) and in adiponectin levels has been associated with increased risk of cardiovascular disease. It is important to emphasize that our findings may have been different in men with overt hypogonadism, i.e. men with low testosterone levels and symptoms of hypogonadism, and we cannot exclude a significant effect of testosterone therapy on insulin sensitivity in overt insulin resistant men, e.g. type 2 diabetes mellitus.

\section{Declaration of interest}

The authors declare that there is no conflict of interest that could be perceived as prejudicing the impartiality of the research reported.

\section{Funding}

This research did not receive any specific grant from any funding agency in the public, commercial or not-for-profit sector. 


\section{Acknowledgements}

We thank the Novo Nordisk Foundation, Ipsen Scandinavia for kindly providing Testim and placebo and the Clinical Institute - University of Southern Denmark. Mrs Hanne Petersen and Karen Mathiassen are thanked for skilled laboratory assistance with the adiponectin measurements.

\section{References}

1 O'Connell MD, Tajar A, Roberts SA \& Wu FC. Do androgens play any role in the physical frailty of ageing men? International Journal of Andrology 201034 195-211. (doi:10.1111/j.13652605.2010.01093.x)

2 Frederiksen L, Hojlund K, Hougaard DM, Brixen K \& Andersen M. Testosterone therapy increased muscle mass and lipid oxidation in aging men. Age, 2012. In Press. (doi:10.1007/s11357-011-9213-9)

3 Manolopoulos KN, Karpe F \& Frayn KN. Gluteofemoral body fat as a determinant of metabolic health. International Journal of Obesity 201034 949-959. (doi:10.1038/ijo.2009.286)

4 Frederiksen L, Nielsen TL, Wraae K, Hagen C, Frystyk J, Flyvbjerg A, Brixen K \& Andersen M. Subcutaneous rather than visceral adipose tissue is associated with adiponectin levels and insulin resistance in young men. Journal of Clinical Endocrinology and Metabolism 200994 4010-4015. (doi:10.1210/jc.20090980)

5 Xu A, Chan KW, Hoo RL, Wang Y, Tan KC, Zhang J, Chen B, Lam MC, Tse C, Cooper GJ \& Lam KS. Testosterone selectively reduces the high molecular weight form of adiponectin by inhibiting its secretion from adipocytes. Journal of Biological Chemistry 2005280 18073-18080. (doi:10.1074/jbc.M414 231200)

6 Emmelot-Vonk MH, Verhaar HJ, Nakhai Pour HR, Aleman A, Lock TM, Bosch JL, Grobbee DE \& van der Schouw YT. Effect of testosterone supplementation on functional mobility, cognition, and other parameters in older men: a randomized controlled trial. Journal of the American Medical Association 2008299 39-52. (doi:10.1001/jama.2007.51)

7 Marin P, Holmang S, Jonsson L, Sjostrom L, Kvist H, Holm G, Lindstedt G \& Bjorntorp P. The effects of testosterone treatment on body composition and metabolism in middle-aged obese men. International Journal of Obesity and Related Metabolic Disorders 1992 16 991-997.

8 Schroeder ET, Zheng L, Ong MD, Martinez C, Flores C, Stewart Y, Azen C \& Sattler FR. Effects of androgen therapy on adipose tissue and metabolism in older men. Journal of Clinical Endocrinology and Metabolism 200489 4863-4872. (doi:10.1210/jc.2004-0784)

9 Munzer T, Harman SM, Hees P, Shapiro E, Christmas C, Bellantoni MF, Stevens TE, O'Connor KG, Pabst KM, St Clair C, Sorkin JD \& Blackman MR. Effects of GH and/or sex steroid administration on abdominal subcutaneous and visceral fat in healthy aged women and men. Journal of Clinical Endocrinology and Metabolism 200186 3604-3610. (doi:10.1210/jc.86.8.3604)

10 Svartberg J, Agledahl I, Figenschau Y, Sildnes T, Waterloo K \& Jorde R. Testosterone treatment in elderly men with subnormal testosterone levels improves body composition and BMD in the hip. International Journal of Impotence Research 200820 378-387. (doi:10.1038/ijir.2008.19)

11 Marin P, Holmang S, Gustafsson C, Jonsson L, Kvist H, Elander A, Eldh J, Sjostrom L, Holm G \& Bjorntorp P. Androgen treatment of abdominally obese men. Obesity Research 19931 245-251.

12 Kapoor D, Clarke S, Stanworth R, Channer KS \& Jones TH. The effect of testosterone replacement therapy on adipocytokines and C-reactive protein in hypogonadal men with type 2 diabetes. European Journal of Endocrinology 2007156 595-602. (doi:10. 1530/EJE-06-0737)
13 Page ST, Herbst KL, Amory JK, Coviello AD, Anawalt BD, Matsumoto AM \& Bremner WJ. Testosterone administration suppresses adiponectin levels in men. Journal of Andrology 2005 26 85-92.

14 Page ST, Amory JK, Bowman FD, Anawalt BD, Matsumoto AM, Bremner WJ \& Tenover JL. Exogenous testosterone (T) alone or with finasteride increases physical performance, grip strength, and lean body mass in older men with low serum T. Journal of Clinical Endocrinology and Metabolism 200590 1502-1510. (doi:10. 1210/jc.2004-1933)

15 Nielsen TL, Hagen C, Wraae K, Brixen K, Petersen PH, Haug E, Larsen R \& Andersen M. Visceral and subcutaneous adipose tissue assessed by magnetic resonance imaging in relation to circulating androgens, sex hormone-binding globulin, and luteinizing hormone in young men. Journal of Clinical Endocrinology and Metabolism 200792 2696-2705. (doi:10.1210/jc.2006-1847)

16 Mosbech TM, Larsen R \& Vaag A. Automatic segmentation of abdominal adipose tissue in MRI. Lecture Notes in Computer Science, Proceedings of the 17th Scandinavian Conference on Image Analysis 1-1-2011.

17 Vermeulen A, Verdonck L \& Kaufman JM. A critical evaluation of simple methods for the estimation of free testosterone in serum. Journal of Clinical Endocrinology and Metabolism $1999 \mathbf{8 4}$ 3666-3672. (doi:10.1210/jc.84.10.3666)

18 Frystyk J, Tarnow L, Hansen TK, Parving HH \& Flyvbjerg A. Increased serum adiponectin levels in type 1 diabetic patients with microvascular complications. Diabetologia 200548 1911-1918. (doi:10.1007/s00125-005-1850-z)

19 Hother-Nielsen O, Henriksen JE, Holst JJ \& Beck-Nielsen H. Effects of insulin on glucose turnover rates in vivo: isotope dilution versus constant specific activity technique. Metabolism 199645 82-91. (doi:10.1016/S0026-0495(96)90204-8)

20 Vickers AJ \& Altman DG. Statistics notes: analysing controlled trials with baseline and follow up measurements. BMJ 2001323 1123-1124. (doi:10.1136/bmj.323.7321.1123)

21 Altman DG. Clinical trials. In Practical Statistics for Medical Research, pp 440-478. London: Chapmann and Hall, 1999.

22 Wang C, Catlin DH, Demers LM, Starcevic B \& Swerdloff RS. Measurement of total serum testosterone in adult men: comparison of current laboratory methods versus liquid chromatographytandem mass spectrometry. Journal of Clinical Endocrinology and Metabolism 200489 534-543. (doi:10.1210/jc.2003-031287)

23 Isidori AM, Giannetta E, Greco EA, Gianfrilli D, Bonifacio V, Isidori A, Lenzi A \& Fabbri A. Effects of testosterone on body composition, bone metabolism and serum lipid profile in middle-aged men: a meta-analysis. Clinical Endocrinology 2005 63 280-293. (doi:10.1111/j.1365-2265.2005.02339.x)

24 Allan CA, Strauss BJ, Burger HG, Forbes EA \& McLachlan RI. Testosterone therapy prevents gain in visceral adipose tissue and loss of skeletal muscle in nonobese aging men. Journal of Clinical Endocrinology and Metabolism 200893 139-146. (doi:10.1210/ jc.2007-1291)

25 Mhatre AN, Trifiro MA, Kaufman M, Kazemi-Esfarjani P, Figlewicz D, Rouleau G \& Pinsky L. Reduced transcriptional regulatory competence of the androgen receptor in X-linked spinal and bulbar muscular atrophy. Nature Genetics 19935 184-188. (doi:10.1038/ng1093-184)

26 Tut TG, Ghadessy FJ, Trifiro MA, Pinsky L \& Yong EL. Long polyglutamine tracts in the androgen receptor are associated with reduced trans-activation, impaired sperm production, and male infertility. Journal of Clinical Endocrinology and Metabolism 199782 3777-3782. (doi:10.1210/jc.82.11.3777)

27 Nielsen TL, Hagen C, Wraae K, Bathum L, Larsen R, Brixen K \& Andersen M. The impact of the CAG repeat polymorphism of the androgen receptor gene on muscle and adipose tissues in 20-29year-old Danish men: Odense Androgen Study. European Journal of Endocrinology 2010162 795-804. (doi:10.1530/EJE-09-0763)

28 Swarbrick MM \& Havel PJ. Physiological, pharmacological, and nutritional regulation of circulating adiponectin concentrations in humans. Metabolic Syndrome and Related Disorders 20086 87-102. (doi:10.1089/met.2007.0029) 
29 Kadowaki T, Yamauchi T, Kubota N, Hara K, Ueki K \& Tobe K. Adiponectin and adiponectin receptors in insulin resistance, diabetes, and the metabolic syndrome. Journal of Clinical Investigation 2006116 1784-1792. (doi:10.1172/JCI29126)

30 Fain JN, Madan AK, Hiler ML, Cheema P \& Bahouth SW. Comparison of the release of adipokines by adipose tissue, adipose tissue matrix, and adipocytes from visceral and subcutaneous abdominal adipose tissues of obese humans. Endocrinology 2004 145 2273-2282. (doi:10.1210/en.2003-1336)

31 Fujikawa R, Ito C, Nakashima R, Orita Y \& Ohashi N. Is there any association between subcutaneous adipose tissue area and plasma total and high molecular weight adiponectin levels? Metabolism 200857 506-510. (doi:10.1016/j.metabol.2007.11.012)

32 Lanfranco F, Zitzmann M, Simoni M \& Nieschlag E. Serum adiponectin levels in hypogonadal males: influence of testosterone replacement therapy. Clinical Endocrinology 200460 500-507. (doi:10.1111/j.1365-2265.2004.02007.x)

$33 \mathrm{Xu} \mathrm{X}$, De PG \& Bjorntorp P. The effects of androgens on the regulation of lipolysis in adipose precursor cells. Endocrinology 1990126 1229-1234. (doi:10.1210/endo-126-2-1229)

34 Rebuffe-Scrive M, Marin P \& Bjorntorp P. Effect of testosterone on abdominal adipose tissue in men. International Journal of Obesity $199115791-795$.

35 Plaisance EP, Grandjean PW, Judd RL, Jones KW \& Taylor JK. The influence of sex, body composition, and nonesterified fatty acids on serum adipokine concentrations. Metabolism 200958 15571563. (doi:10.1016/j.metabol.2009.04.038)

36 Fasshauer M, Klein J, Neumann S, Eszlinger M \& Paschke R. Adiponectin gene expression is inhibited by beta-adrenergic stimulation via protein kinase A in 3T3-L1 adipocytes. FEBS Letters $2001 \mathbf{5 0 7}$ 142-146. (doi:10.1016/S0014-5793(01) 02960-X)

37 Wang Y, Lam KS, Yau MH \& Xu A. Post-translational modifications of adiponectin: mechanisms and functional implications. Biochemical Journal 2008409 623-633. (doi:10.1042/ BJ20071492)

38 Andersen KK, Frystyk J, Wolthers OD, Heuck C \& Flyvbjerg A. Gender differences of oligomers and total adiponectin during puberty: a cross-sectional study of 859 Danish school children. Journal of Clinical Endocrinology and Metabolism 200792 1857-1862. (doi:10. 1210/jc.2006-2310)

39 Yamauchi T, Kamon J, Minokoshi Y, Ito Y, Waki H, Uchida S, Yamashita S, Noda M, Kita S, Ueki K, Eto K, Akanuma Y, Froguel P,
Foufelle F, Ferre P, Carling D, Kimura S, Nagai R, Kahn BB \& Kadowaki T. Adiponectin stimulates glucose utilization and fattyacid oxidation by activating AMP-activated protein kinase. Nature Medicine 20028 1288-1295. (doi:10.1038/nm788)

40 Whitsel EA, Boyko EJ, Matsumoto AM, Anawalt BD \& Siscovick DS. Intramuscular testosterone esters and plasma lipids in hypogonadal men: a meta-analysis. American Journal of Medicine 2001111 261-269. (doi:10.1016/S0002-9343(01)00833-6)

41 Fernandez-Balsells MM, Murad MH, Lane M, Lampropulos JF, Albuquerque F, Mullan RJ, Agrwal N, Elamin MB, GallegosOrozco JF, Wang AT, Erwin PJ, Bhasin S \& Montori VM. Clinical review 1: adverse effects of testosterone therapy in adult men: a systematic review and meta-analysis. Journal of Clinical Endocrinology and Metabolism 201095 2560-2575. (doi:10.1210/jc. 2009-2575)

42 Jones TH, Arver S, Behre HM, Buvat J, Meuleman E, Moncada I, Morales AM, Volterrani M, Yellowlees A, Howell JD \& Channer KS. Testosterone replacement in hypogonadal men with type 2 diabetes and/or metabolic syndrome (the TIMES2 Study). Diabetes Care 201134 828-837. (doi:10.2337/dc10-1233)

43 Kalinchenko SY, Tishova YA, Mskhalaya GJ, Gooren LJ, Giltay EJ \& Saad F. Effects of testosterone supplementation on markers of the metabolic syndrome and inflammation in hypogonadal men with the metabolic syndrome: the double-blinded placebo-controlled Moscow study. Clinical Endocrinology 201073 602-612. (doi:10. $1111 /$ j.1365-2265.2010.03845.x)

44 Nair KS, Rizza RA, O'Brien P, Dhatariya K, Short KR, Nehra A, Vittone JL, Klee GG, Basu A, Basu R, Cobelli C, Toffolo G, Dalla MC, Tindall DJ, Melton LJ III, Smith GE, Khosla S \& Jensen MD. DHEA in elderly women and DHEA or testosterone in elderly men. $N$ Engl J Med 2006355 1647-1659.

45 Kapoor D, Goodwin E, Channer KS \& Jones TH. Testosterone replacement therapy improves insulin resistance, glycaemic control, visceral adiposity and hypercholesterolaemia in hypogonadal men with type 2 diabetes. Eur J Endocrinol $2006 \mathbf{1 5 4}$ 899-906.

Received 21 March 2011

Revised version received 26 October 2011

Accepted 21 December 2011 